\title{
Pretreatment and Fractionation of Wheat Straw by an Acetone-Based Organosolv Process
}

\author{
W.J.J. Huijgen \\ J.H. Reith \\ H. den Uil
}

Published in Ind. Eng. Chem. Res. 2010, 49, 10132-10140 


\title{
Pretreatment and Fractionation of Wheat Straw by an Acetone-Based Organosolv Process
}

\author{
Wouter J. J. Huijgen,* Johannes H. Reith, and Herman den Uil \\ Energy Research Centre of The Netherlands (ECN), Biomass, Coal \& Environmental Research, \\ P.O. Box 1, 1755 ZG Petten, The Netherlands
}

\begin{abstract}
Acetone-based organosolv fractionation of wheat straw was studied to produce sugars and lignin in a lignocellulose biorefinery. The influence of acetone-water ratio, reaction time, and temperature on fractionation degree, lignin yield, and enzymatic digestibility of the cellulose fraction was examined. The solvent-water ratio was found to influence delignification and hemicellulose hydrolysis by its effect on lignin solubility and $\mathrm{pH}$. Organosolv treatment in 50:50\% w/w acetone-water during $1 \mathrm{~h}$ at $205^{\circ} \mathrm{C}$ resulted in $82 \%$ hemicellulose hydrolysis, $79 \%$ delignification, and $93 \%$ cellulose recovery. A substantial part of the sugars formed upon hemicellulose hydrolysis seems to have reacted further including possible formation of lignin-furfural condensation products. Finally, aqueous acetone pretreatment was found to substantially improve the enzymatic digestibility of the cellulose fraction (glucose yield: up to $87 \%$ vs $16 \%$ for untreated wheat straw).
\end{abstract}

\section{Introduction}

In a lignocellulose biorefinery, second generation biofuels and chemicals are produced from the different chemical constituents of the biomass feedstock (mainly cellulose, hemicellulose, and lignin). The cellulose fraction of the biomass can, for example, be converted into sugars for the production of bioethanol or other fermentation products. For this process, pretreatment is required to overcome the recalcitrance of cellulose to enzymatic hydrolysis. ${ }^{1}$ Improvement of the accessibility of the cellulose polymers for hydrolyzing enzymes can be established by, for example, removing hemicellulose and lignin from the biomass, reducing the crystallinity of the cellulose fibers, and increasing their surface area. ${ }^{1,2}$ For this purpose, various pretreatment technologies are being developed including steam explosion, acid pretreatment, and ammonia-fiber explosion. ${ }^{1,2}$

In organosolv pretreatment, biomass is treated thermally in the presence of an organic solvent. Organosolv was originally developed as pulping process for paper making, ${ }^{3,4}$ but has also been studied as pretreatment technology for the fermentative production of, for example, bioethanol from lignocellulose..$^{1,5-8}$ One of the main benefits of organosolv fractionation as compared to other pretreatment processes is that the use of an organic solvent enables effective delignification of the biomass prior to enzymatic hydrolysis, while largely preserving the chemical structure of the lignin fraction. Thus, the lignin fraction of the biomass can be recovered with a high purity. In most other pretreatment processes, lignin ends up in a residue together with nonhydrolyzed sugar polymers, feedstock minerals, and process chemicals. This type of residue seems mostly suited as fuel for heat and power generation. From organosolv lignin, valuable products like resins and phenol(ics) can potentially be produced. ${ }^{9,10}$ Full valorization of both the sugars and the lignin present in lignocellulose would substantially improve the cost effectiveness of a biorefinery.

Various solvents have been applied for organosolv pulping or pretreatment. ${ }^{1,5,11}$ Ethanol is most often used, being a relatively cheap and effective delignification solvent. Moreover, recycling of the ethanol solvent is facilitated by its volatility and process integration possibilities in case of bioethanol

* To whom correspondence should be addressed. Tel.: +31-224568162. Fax: +31-224-568487. E-mail: huijgen@ecn.nl. production. However, the solubility of lignin in acetone is significantly higher than in ethanol (Figure 1). Thus, the use of acetone might potentially improve delignification of the biomass and thereby further enhance the lignin recovery and the enzymatic digestibility of the cellulose fraction.

Wheat straw is one of the largest agricultural residue streams available in the European Union. Acetone-based organosolv treatment of wheat straw has been studied previously, ${ }^{12,13}$ but with the aim of pulping for paper production. For lignocellulose in general, most work on acetone-based organosolv pretreatment for enzymatic hydrolysis thus far has been performed on mineral acid-catalyzed processes. ${ }^{5}$ The use of mineral acids, however, has drawbacks, including possible corrosion and the need for neutralization leading to waste production. For solvents other than acetone, effective organosolv treatment of herbaceous plants including wheat straw without the use of mineral acids has been reported. 5,11

In this Article, we present a study on acetone-based organosolv fractionation of wheat straw without the use of mineral acids to produce sugars and lignin in a lignocellulose biorefinery. The study will first focus on the influence of the main process parameters on the fractionation of the straw (i.e., degree of delignification, hemicellulose hydrolysis, and cellulose recovery)

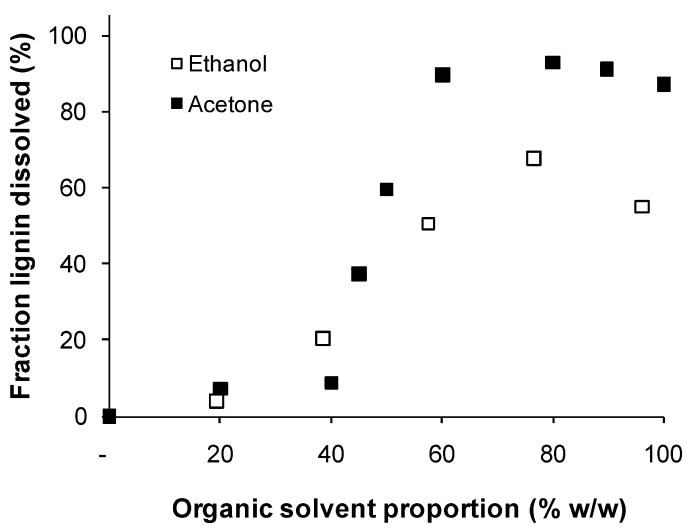

Figure 1. Measured solubility of Alcell lignin in mixtures of ethanol-water and acetone-water. Solubility expressed as fraction dissolved of initial $100 \mathrm{~g}$ lignin/L solvent mixture. Observed solubility trends are similar to those reported for ethanol-water mixtures by $\mathrm{Ni}$ et al. ${ }^{33}$ 
Table 1. Process Conditions of the Organosolv Experiments

\begin{tabular}{cccc}
\hline \multirow{2}{*}{ experimental series } & \multicolumn{3}{c}{ process conditions } \\
\cline { 2 - 4 } & acetone $/ \mathrm{H}_{2} \mathrm{O}(\% \mathrm{w} / \mathrm{w})$ & $t(\mathrm{~min})$ & $T\left({ }^{\circ} \mathrm{C}\right)$ \\
\hline \multirow{2}{*}{ acetone: $\mathrm{H}_{2} \mathrm{O}$} & $0: 100$ & 60 & 190 \\
& $25: 75$ & 60 & 190 \\
& $40: 60$ & 60 & 190 \\
& $50: 50$ & 60 & 190 \\
$t$ & $60: 40$ & 60 & 190 \\
& $50: 50$ & 0 & 190 \\
& $50: 50$ & 15 & 190 \\
& $50: 50$ & 30 & 190 \\
& $50: 50$ & 60 & 190 \\
& $50: 50$ & 120 & 190 \\
& $50: 50$ & 60 & 160 \\
& $50: 50$ & 60 & 175 \\
& $50: 50$ & 60 & 190 \\
& $50: 50$ & 60 & 205 \\
& $50: 50$ & 60 & 220
\end{tabular}

as well as the separation of the lignin from the organosolv liquor. Subsequently, the effect of organosolv pretreatment on the enzymatic digestibility of the cellulose-enriched pulp will be assessed.

\section{Materials and Methods}

2.1. Feedstock. Wheat straw cut to $<2 \mathrm{~cm}$ was received ambient-dry from Spain and stored at room temperature in a closed vessel. A representative subsample was taken for the organosolv experiments and used without further treatment. The average moisture content of the raw material was $\sim 8 \%$ w/w. The biochemical composition of the wheat straw was determined as (\% w/w, dry biomass): extractives $\mathrm{H}_{2} \mathrm{O}, 11.2 \pm 1.2$; extractives EtOH, $2.0 \pm 0.0$; glucan, $34.6 \pm 1.0$; xylan, $21.5 \pm$ 0.7 ; arabinan, $2.1 \pm 0.1$; galactan, $0.5 \pm 0.0$; mannan, $0.2 \pm$ 0.1 ; acid insoluble lignin, $15.1 \pm 0.1$; acid soluble lignin, 1.0 \pm 0.0 ; and ash, $8.5 \pm 0.2$ (see section 2.5 for the methodology used). The $\mathrm{H}_{2} \mathrm{O}$ extract contained the equivalent of $0.22 \%$ and $0.05 \% \mathrm{w} / \mathrm{w}$ dry biomass of glucan and xylan, respectively (neglected in the calculations presented). The elemental composition of the wheat straw was (\% w/w, dry biomass): C, 43.8; $\mathrm{O}, 41.7 ; \mathrm{H}, 5.4 ; \mathrm{Si}, 2.4 ; \mathrm{K}, 1.4 ; \mathrm{Cl}, 0.5 ; \mathrm{N}, 0.2$; and $\mathrm{Ca}, 0.2)$ (other elements $<0.1$ ).

2.2. Organosolv Experiments. Organosolv experiments were performed in an autoclave reactor $(0.5 \mathrm{~L}$ Hastelloy Kiloclave, Büchi Glas Uster AG, CH). A suspension of wheat straw, demineralized water, and acetone with a fixed liquid-tosolid ratio ( $\mathrm{L} / \mathrm{S}=14.2 \mathrm{~g}$ solvent $/ \mathrm{g}$ dw biomass) and a variable acetone-water ratio (0:100-60:40\% w/w acetone-water) was mixed with an anchor stirrer at a rate of $100 \mathrm{rpm}$. After the reactor was heated to the reaction temperature $\left(T, 160-220^{\circ} \mathrm{C}\right)$, the reactor was kept isothermal during the reaction time $(t$, $0-120 \mathrm{~min}$ ), and subsequently cooled to below $40^{\circ} \mathrm{C}$. Process conditions were varied around a reference experiment (acetonewater $50-50 \% \mathrm{w} / \mathrm{w}, 190{ }^{\circ} \mathrm{C}, 60 \mathrm{~min}$ ). Table 1 gives an overview of the experiments performed. Reference experiment conditions have been selected as the starting point for this study based on earlier experience with ethanol-based organosolv. ${ }^{14}$ In Figure 2 , the temperature and pressure profiles recorded during the reference organosolv experiment are shown. In this experiment, the heating (from 30 to $190{ }^{\circ} \mathrm{C}$ ) and cooling (from 190 to 40 ${ }^{\circ} \mathrm{C}$ ) times were 45 and $32 \mathrm{~min}$, respectively.

After organosolv treatment, the product suspension was filtered quantitatively over a Whatman type 3 paper-filter. The filtrate or "organosolv liquor" was stored in a refrigerator for analysis and lignin recovery. The solid fraction remaining after organosolv was washed and dried overnight in a vacuum oven

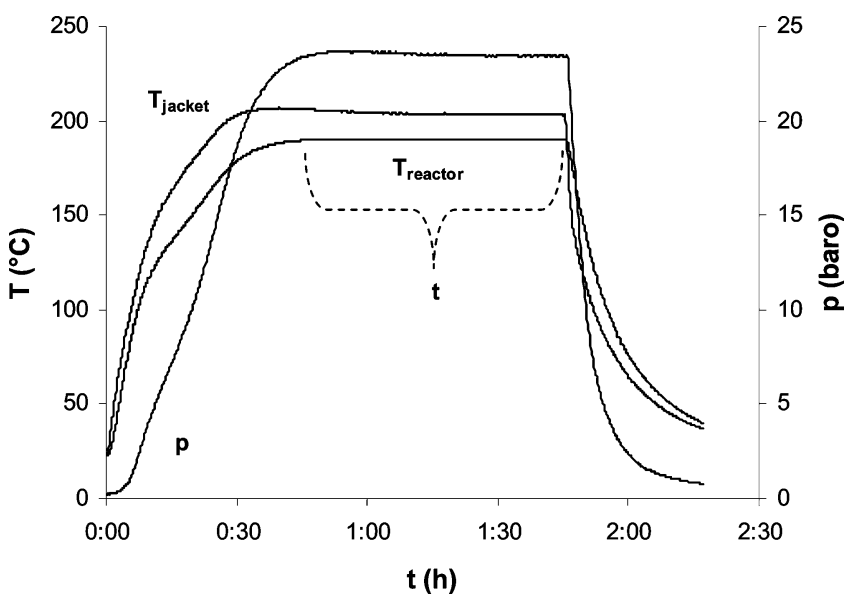

Figure 2. The temperature and pressure profile recorded during the organosolv reference experiment $\left(T=190{ }^{\circ} \mathrm{C}, t=60 \mathrm{~min}, 50-50 \% \mathrm{w} / \mathrm{w}\right.$ acetone-water). During the reaction time $(t)$, the reactor is isothermal at its temperature set-point $\pm 0.2{ }^{\circ} \mathrm{C}$.

at $50{ }^{\circ} \mathrm{C}$. Subsequently, the pulp yield was calculated $(\% \mathrm{dw}$ recovered solids/dw starting material). For washing, an acetone-water mixture was used in similar amount and with the same acetone-water ratio as the solvent applied in the organosolv process itself. The resulting washing liquor was also stored in a refrigerator for lignin recovery.

2.3. Analysis of Organosolv Liquor. The organosolv liquor was analyzed for sugars including glucose and xylose (HPAECPAD, Dionex ICS3000). The sugar analyses were performed both directly and following posthydrolysis of the sample for conversion of oligomeric sugars into monomeric sugars (posthydrolysis conditions: $1 \mathrm{M} \mathrm{H}_{2} \mathrm{SO}_{4}, 100{ }^{\circ} \mathrm{C}, 2 \mathrm{~h}$ ). The difference between the two analyses was used to determine the concentration of oligomeric sugars in the organosolv liquor.

In addition, the organosolv liquor was analyzed for the sugar dehydration products HMF (5-(hydroxymethyl)-2-furaldehyde) and furfural (furan-2-carbaldehyde) as well as the organic acids acetic, formic, and levulinic acid (GC-MS, Trace GC ultra DSQ II, Thermo Scientific, with Phenomenex ZB WAX plus column). Samples were diluted with 2-propanol before GC-MS analysis.

2.4. Lignin Recovery from Organosolv Liquor. Lignin was precipitated from the organosolv liquor and the washing solution upon dilution with refrigerated water (water:solution 3:1 w/w) (see Figure 1 for the influence of acetone-water ratio on lignin solubility). The lignin-containing acetone-water solution was sprayed into the cold water, thus causing immediate dilution of the mixture and incorporation of small air bubbles giving buoyancy to the lignin particles formed. ${ }^{15}$ The resulting mixture was left at room temperature for at least 30 min until all lignin particles floated on top of the solution. After sedimentation of the particles by centrifugation, the supernatant was decanted, and the lignin was dried and weighed.

2.5. Composition Analysis of Solids. The moisture and ash contents of the raw material and pretreated wheat straw samples were measured according to the protocols NREL/TP-510-42621 and 42622, respectively. ${ }^{16}$ The biochemical composition (i.e., content of extractives, lignin, and (hemi)cellulose) of these solids was determined in duplicate by using a modified hydrolysis protocol based on TAPPI methods T 222 and $249 .{ }^{17}$ First, in the case of the raw material, extractives were removed with two successive Soxhlet extractions using water and ethanol (NREL/TP-510-42619 ${ }^{16}$ ). Extractions were performed on two samples of fresh wheat straw, and both extracted samples were analyzed for their biochemical composition. The average composition and the deviation between the two samples were 
Table 2. Pulp Yield and Composition of Fresh and Pretreated Wheat Straw

\begin{tabular}{|c|c|c|c|c|c|c|c|c|c|c|c|c|c|}
\hline \multirow[b]{3}{*}{ experimental series } & & \multirow[b]{3}{*}{ pulp yield $(\mathrm{dw} \%)^{a}$} & \multicolumn{11}{|c|}{ biochemical composition $(\% \mathrm{w} / \mathrm{w} \text { dry biomass })^{b}$} \\
\hline & & & \multicolumn{2}{|c|}{ extractives } & \multicolumn{2}{|c|}{ lignin } & \multirow[b]{2}{*}{ arabinan } & \multirow[b]{2}{*}{ xylan } & \multirow[b]{2}{*}{ mannan } & \multirow[b]{2}{*}{ galactan } & \multirow[b]{2}{*}{ glucan } & \multirow[b]{2}{*}{ ash } & \multirow[b]{2}{*}{ total } \\
\hline & & & $\mathrm{H}_{2} \mathrm{O}$ & $\mathrm{EtOH}$ & AIL & ASL & & & & & & & \\
\hline \multirow[t]{3}{*}{ acetone $: \mathrm{H}_{2} \mathrm{O}(\% \mathrm{w} / \mathrm{w})$} & $0: 100^{c}$ & 59.7 & & & 30.4 & 1.0 & 0.0 & 2.4 & 0.0 & 0.0 & 53.0 & 6.8 & 93.5 \\
\hline & $25: 75^{c}$ & 55.5 & & & 19.8 & 0.6 & 0.0 & 5.3 & 0.2 & 0.0 & 59.2 & 8.7 & 93.7 \\
\hline & $40: 60$ & 54.4 & & & 8.6 & 0.7 & 0.2 & 11.6 & 0.2 & 0.0 & 57.1 & 10.1 & 88.5 \\
\hline \multirow[t]{5}{*}{$t(\min )$} & 0 & 78.7 & & & 14.8 & 1.3 & 1.6 & 21.6 & 0.4 & 0.5 & 40.2 & 7.3 & 87.7 \\
\hline & 15 & 70.4 & & & 13.0 & 1.1 & 1.0 & 21.3 & 0.6 & 0.2 & 45.2 & 7.6 & 90.0 \\
\hline & 30 & 65.1 & & & 11.4 & 1.0 & 0.6 & 18.9 & 0.6 & 0.2 & 47.5 & 8.4 & 88.7 \\
\hline & 60 & 56.0 & & & 8.5 & 0.9 & 0.2 & 16.0 & 0.4 & 0.2 & 56.7 & 9.8 & 92.7 \\
\hline & 120 & 51.9 & & & 6.4 & 0.7 & 0.0 & 12.9 & 0.3 & 0.0 & 59.2 & 10.6 & 90.1 \\
\hline \multirow{2}{*}{$T\left({ }^{\circ} \mathrm{C}\right)$} & 160 & 82.8 & & & 15.9 & 1.3 & 1.8 & 22.2 & 0.0 & 0.5 & 40.3 & 6.8 & 88.9 \\
\hline & 175 & 72.9 & & & 13.5 & 1.2 & 1.1 & 20.9 & 0.0 & 0.2 & 45.7 & 8.0 & 90.6 \\
\hline
\end{tabular}

${ }^{a} \mathrm{dw}$ : dry weight. ${ }^{b}$ Average of duplicate analyses (for fresh wheat straw, extractions and composition determined on two feedstock subsamples). ${ }^{c}$ Shorter sample milling time prior to hydrolysis $(45 \mathrm{~s})$ because samples turned into dust during standard milling (180 s).

determined (for results, see section 2.1). No extractions were performed on pretreated materials, because it was assumed that extractives had been removed during the organosolv treatment itself. Second, the sample was milled with a cutting mill (see also Table 2) and hydrolyzed in two steps: (1) $72 \%$ w/w $\mathrm{H}_{2} \mathrm{SO}_{4}$ $\left(30{ }^{\circ} \mathrm{C}, 1 \mathrm{~h}\right)$ and $(2) 4 \% \mathrm{w} / \mathrm{w} \mathrm{H}_{2} \mathrm{SO}_{4}\left(100{ }^{\circ} \mathrm{C}, 3 \mathrm{~h}\right)$. During both hydrolysis steps, the slurries were well mixed. Third, the product slurry was filtered, and the solid residue was washed, dried, and weighed. After determination of the ash content of the residue by combustion at $550{ }^{\circ} \mathrm{C}\left(\mathrm{NREL} / \mathrm{TP}-510-42618^{16}\right)$, the acid-insoluble lignin (AIL) content was calculated on the basis of the weight of the ash-free residue. Finally, the hydrolysate was analyzed for the sugars glucose, xylose, arabinose, galactose, and mannose (HPAEC-PAD) as well as acid-soluble lignin (ASL, UV-vis absorption at $205 \mathrm{~nm}$ ). A reference sample (willow wood pretreated with ethanol-based organosolv) was included in each series of biochemical composition analyses, yielding an average AIL, ASL, glucan, and xylan content of $30.1 \pm 0.6(n=7), 0.6 \pm 0.1(n=6), 46.8 \pm 0.6(n=3)$, and $8.6 \pm 0.4(n=3) \mathrm{dw} \%$, respectively $(2 \sigma)$.

On the basis of the pulp yield and the biochemical composition of the fresh and pretreated wheat straw, the degrees of delignification, hemicellulose hydrolysis, and cellulose recovery of the organosolv process were calculated. In these calculations, for lignin the sum of AIL and ASL was used. The hemicellulose fraction was assumed to consist only of xylan, and the glucan content was solely attributed to the cellulose fraction.

2.6. Enzymatic Digestibility. The enzymatic digestibility of fresh and pretreated wheat straw was measured in duplicate according to NREL/TP-510-42629. ${ }^{16}$ A suspension of $1.5 \mathrm{~g} \mathrm{dw}$ of biomass, $50 \mathrm{~mL}$ of $0.05 \mathrm{M} \mathrm{Na}$-acetate buffer ( $\mathrm{pH} 4.8$ ), and an antibiotic to eliminate potential bacterial growth $(30 \mu \mathrm{L}$ of PenStrep, $5000 \mathrm{U} / \mathrm{mL}$ penicillin, and $5 \mathrm{mg} / \mathrm{mL}$ streptomycin) was shaken in an incubator. After the mixture was heated to 50 ${ }^{\circ} \mathrm{C}, 0.8 \mathrm{~mL}$ of enzyme was added (Genencor, Accellerase 1000), and incubation was continued for $72 \mathrm{~h}$. At fixed times, samples were taken from the mixture for glucose determination. The enzymatic glucose yield was calculated on the basis of the mean glucose concentration in the hydrolysate after $72 \mathrm{~h}$ and the glucan content of the substrate. Endoglucanase and $\beta$-glucosidase activities of the enzyme used are $2500 \mathrm{CMC} \mathrm{U/g}$ and 400 pNPG U/g, respectively (specified by the supplier, both minimum values). Cellulase activity, determined according to the protocol of Ghose, ${ }^{18}$ was $72 \mathrm{FPU} / \mathrm{mL}$ (filter paper units) (or 38
FPU/g dry biomass). The enzyme dose used has not been optimized. The dose is anticipated to be sufficiently high to ensure an excess of enzyme, which enables determination of solely the effect of pretreatment on the enzymatic digestibility.

Glucose concentrations in the hydrolysates were determined with a protocol derived from Yee and Goodwin. ${ }^{19}$ Twenty microliters of (diluted) sample was added to $2 \mathrm{~mL}$ of reagent (9\% v/v $o$-toluidine and $1.5 \% \mathrm{w} / \mathrm{v}$ thiourea in glacial acetic acid). After incubation at $90{ }^{\circ} \mathrm{C}(8 \mathrm{~min})$ and cooling with tap water (4 min), absorbance was measured at $635 \mathrm{~nm}$. The measurement accuracy determined for a glucose standard included in every set of samples was $\pm 2.1 \%(2 \sigma)$. Limited interference by other sugars and sugar derivatives may occur during the analysis. The resulting overestimation of the glucose concentration was estimated to be less than $10 \%$ based on glucose determination by HPAEC-PAD in a typical hydrolysate.

A reference sample and two blanks were included in each series of enzymatic hydrolysis tests. The variation in glucose concentrations resulting from the reference samples after $72 \mathrm{~h}$ enzymatic hydrolysis was calculated at $3.6 \%$ between the series $(2 \sigma, n=5)$. In the first blank, the substrate was incubated without the presence of enzyme to assess the presence of glucose (oligomers) in the substrate. In the second blank, no substrate was added to determine the amount of glucose present in the enzyme mixture. Both blanks yielded negligible amounts of glucose in all enzymatic hydrolysis tests performed.

\section{Results and Discussion}

Table 2 shows the pulp yield and the composition of the wheat straw before and after organosolv fractionation. The composition of the organosolv liquors is given in Table 3. The corresponding distribution patterns of lignin, hemicellulose (xylan), and cellulose (glucan) can be found in Figures 3, 4, and 5, respectively.

3.1. Delignification and Lignin Recovery. The acetonewater ratio used for organosolv fractionation is an influential parameter for the delignification of wheat straw (Figure 3). At $190{ }^{\circ} \mathrm{C}$ and $60 \mathrm{~min}$, maximum delignification has occurred at 40:60\% w/w acetone-water. At lower acetone content, delignification is strongly decreased due to the virtual insolubility of lignin in water (Figure 1). At higher acetone content, the reduced delignification cannot be explained solely by the solubility pattern of lignin in acetone-water mixtures. Maxi- 


\begin{tabular}{|c|c|c|c|c|c|c|c|c|c|c|c|}
\hline \multirow[b]{3}{*}{ experimental series } & & \multirow[b]{3}{*}{ liquor recovery $(\% \mathrm{w} / \mathrm{w})^{a}$} & \multirow[b]{3}{*}{$\mathrm{pH}$} & \multicolumn{8}{|c|}{ composition of organosolv liquor (mg/kg liquor) } \\
\hline & & & & \multicolumn{2}{|c|}{ monomeric sugars } & \multicolumn{2}{|c|}{ oligomeric sugars } & \multicolumn{2}{|c|}{ sugar derivatives $^{b}$} & \multicolumn{2}{|c|}{ organic acids } \\
\hline & & & & glucose & xylose & glucose & xylose & HMF & furfural & acetic & formic \\
\hline & $25: 75$ & 56.2 & 4.1 & 63 & 1302 & 602 & 4309 & 91 & 2290 & 2401 & 879 \\
\hline & $40: 60$ & 70.2 & 4.4 & 34 & 387 & 491 & 6070 & 13 & 167 & 2509 & 1035 \\
\hline & $50: 50$ & 73.4 & $c$ & 25 & 229 & 364 & 3934 & 20 & 331 & 2613 & 925 \\
\hline \multirow{4}{*}{$t(\min )$} & 15 & 68.7 & 5.0 & 29 & 61 & 412 & 3436 & $<$ DTL & 65 & 1813 & 356 \\
\hline & 30 & 67.7 & 4.9 & 25 & 100 & 427 & 4539 & 11 & 125 & 2129 & 552 \\
\hline & 60 & 73.4 & & 25 & 229 & 364 & 3934 & 20 & 331 & 2613 & 925 \\
\hline & 120 & 69.3 & 4.5 & 24 & 253 & 334 & 2232 & 33 & 567 & 2899 & 1311 \\
\hline \multirow[t]{3}{*}{$T\left({ }^{\circ} \mathrm{C}\right)$} & 160 & 66.2 & & 113 & 24 & 345 & 654 & $<$ DTL & 12 & 1143 & 144 \\
\hline & 175 & 70.4 & & 47 & 56 & 422 & 2787 & $<$ DTL & 64 & 1741 & 310 \\
\hline & 190 & 73.4 & & 25 & 229 & 364 & 3934 & 20 & 331 & 2613 & 925 \\
\hline
\end{tabular}

${ }^{a}$ Mass organosolv liquor recovered related to mass acetone-water mixture used for organosolv experiment. ${ }^{b}$ In all samples, the concentration of levulinic acid was below the detection limit of $80 \mathrm{mg} / \mathrm{kg} .{ }^{c}$ Not measured. ${ }^{d}$ Below detection limit of $8 \mathrm{mg} / \mathrm{kg}$.
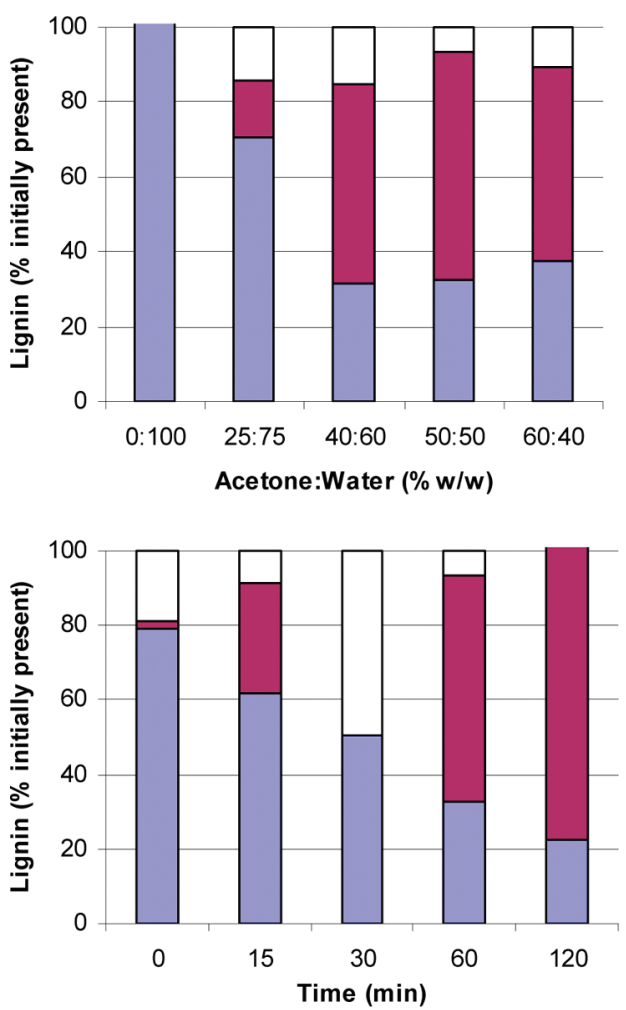

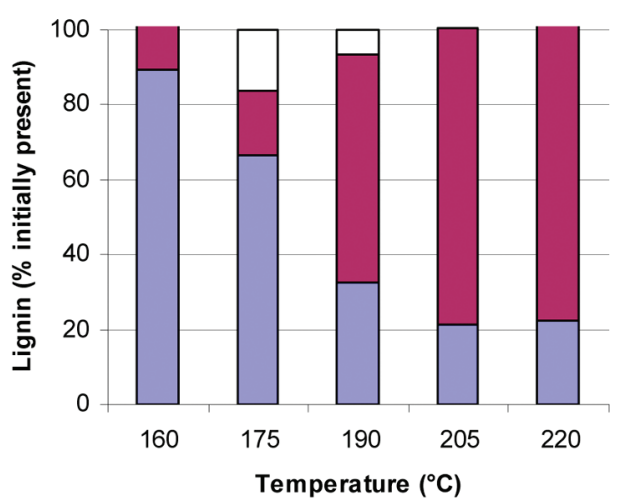

$\square$ Mass losses / degradation $\square$ Recovered from organosolv liquor $\square$ Pretreated solid

Figure 3. Lignin distribution as a function of the acetone:water ratio, reaction time, and reaction temperature $(\%$ w/w of the lignin present in the raw material). Lignin recovered from organosolv liquor includes lignin precipitated from the washing solution. During the 30 min experiment, lignin precipitation was not carried out.

mum lignin solubility is observed at a substantially higher acetone-water ratio, that is, around $80 \% \mathrm{w} / \mathrm{w}$ (Figure 1), than the optimum for delignification, that is, $40 \% \mathrm{w} / \mathrm{w}$. However, the $\mathrm{pH}$ of the organosolv liquor increased with the acetone proportion (Table 3 ). A higher $\mathrm{pH}$ (or lower proton activity) slows the cleavage of bonds within the lignocellulose complex and the lignin itself, resulting in a decrease of the delignification degree ${ }^{5,20}$ Because the concentration of the organic acids formed does not seem to be influenced by the acetone-water ratio (Table 3), the $\mathrm{pH}$ increase is probably caused by a change of the dissociation constant of organic acids with the acetone proportion. At 50:50\% w/w acetone-water, the largest amount of lignin is recovered from the organosolv liquor, that is, $61 \%$ $\mathrm{w} / \mathrm{w}$ of the lignin present in the feedstock or $90 \% \mathrm{w} / \mathrm{w}$ of the lignin present in the organosolv liquor (Figure 3).

The time and temperature graphs in Figure 3 show that delignification increases with pretreatment severity, as has also been reported by Jiménez et al. for acetone-based organosolv pulping of wheat straw. ${ }^{12}$ Severity is defined as the combined effect of temperature and residence time. ${ }^{21}$ An increase of the reaction time from 0 to $120 \mathrm{~min}$ leads to an improvement of the delignification from $21 \%$ to $77 \%\left(190{ }^{\circ} \mathrm{C}, 50: 50 \% \mathrm{w} / \mathrm{w}\right.$ acetone-water). Similarly, elevation of the temperature from 160 to $205^{\circ} \mathrm{C}$ results in an increase of the delignification from $11 \%$ to $79 \%$ (60 $\mathrm{min}, 50: 50 \% \mathrm{w} / \mathrm{w}$ acetone-water). However, a further increase of the temperature to $220{ }^{\circ} \mathrm{C}$ seems to cause 

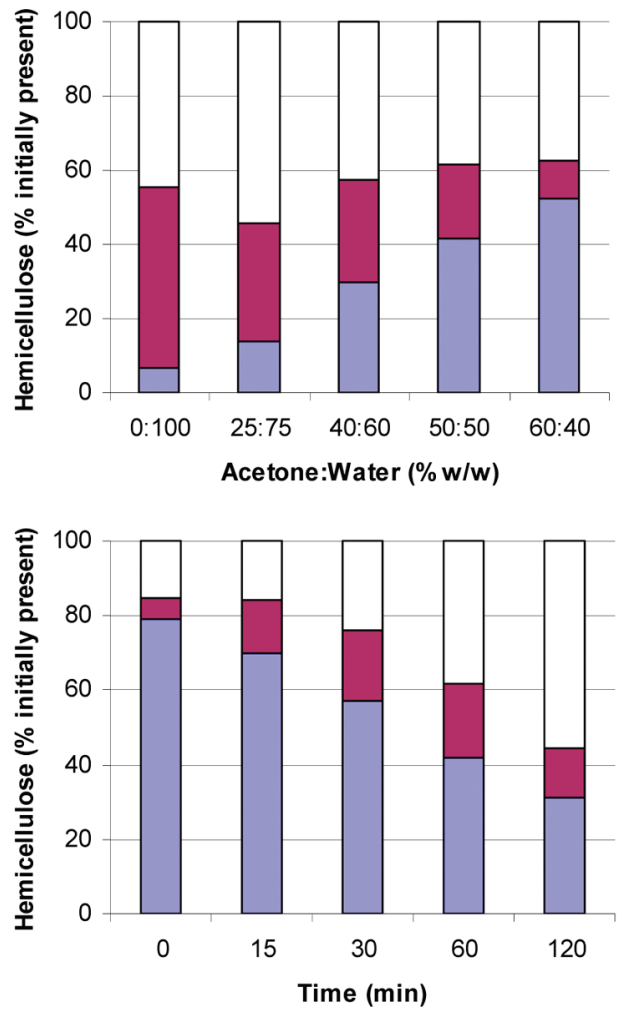

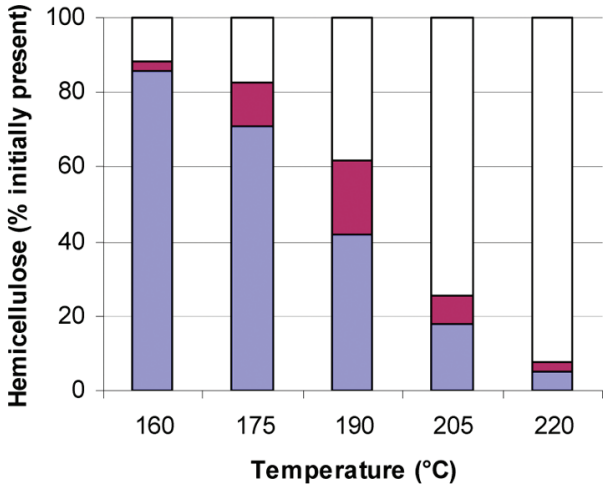

\section{$\square$ Mass losses / degradation \\ $\square$ Organosolv liquor \\ $\square$ Pretreated solid}

Figure 4. Hemicellulose distribution as a function of the acetone:water ratio, reaction time, and reaction temperature (\% w/w of the hemicellulose present in the raw material). The fraction in organosolv liquor consists of monomeric and oligomeric xylose as well as furfural. All furfural is assumed to result from xylose dehydration.
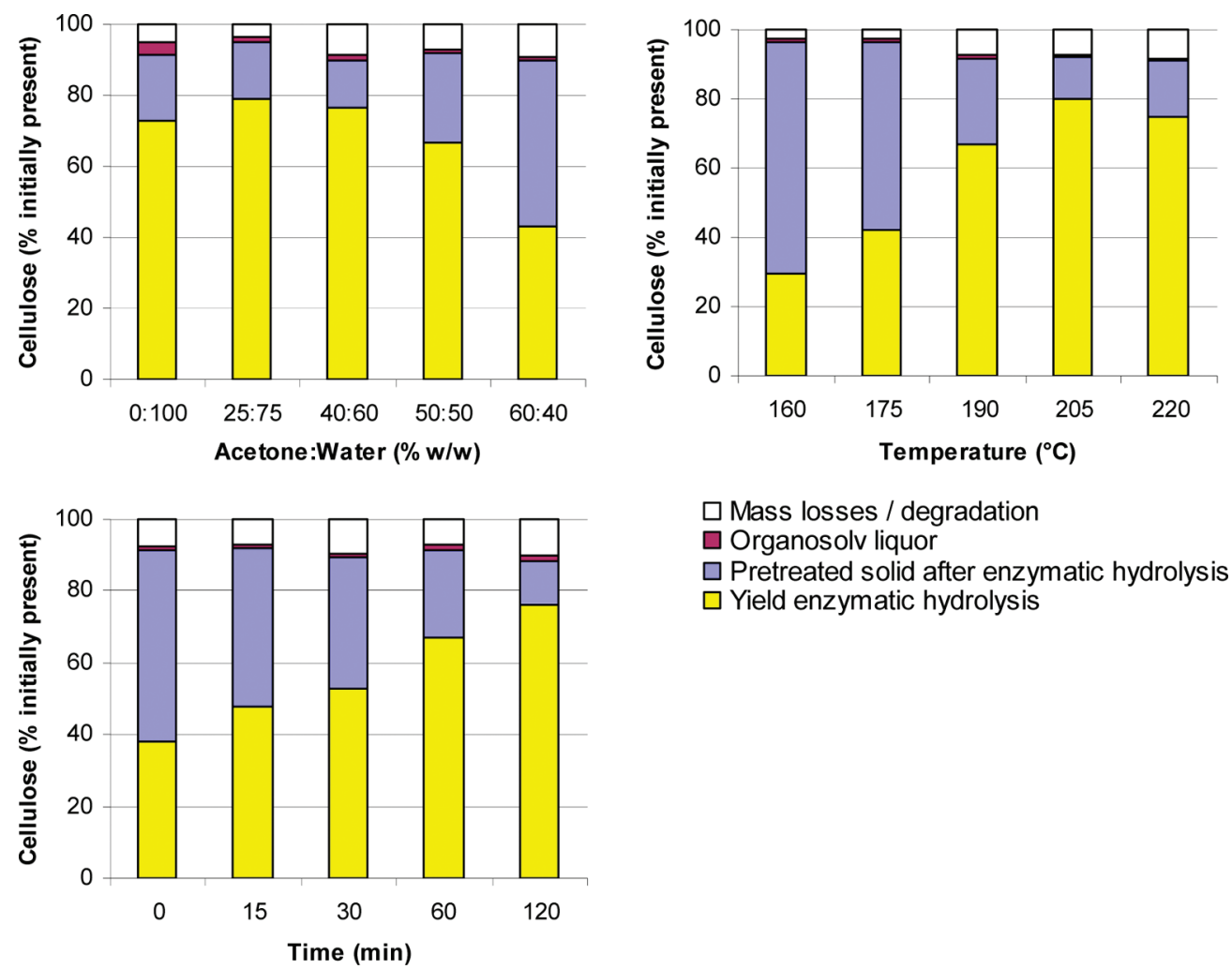

$\square$ Mass losses / degradation

$\square$ Organosolv liquor

$\square$ Pretreated solid after enzymatic hydrolysis

$\square$ Yield enzymatic hydrolysis

Figure 5. Cellulose distribution as a function of the acetone:water ratio, reaction time, and reaction temperature (\% w/w of the cellulose present in the raw material). The fraction in organosolv liquor consists of monomeric and oligomeric glucose as well as HMF.

a small increase of residual lignin content of the pulp (from $7.0 \%$ at $205{ }^{\circ} \mathrm{C}$ to $8.3 \%$ at $220^{\circ} \mathrm{C}$, see Table 2), possibly due to lignin condensation reactions occurring at high temperatures.
The amount of lignin precipitated from the organosolv liquor shows dependencies on process conditions that are similar, but more pronounced than delignification (Figure 3). Thus, increased 
pretreatment severity leads to improved lignin recovery from the organosolv liquor. At the same time, the part of lignin missing in the distribution patterns as shown in Figure 3 decreases with pretreatment severity. In case of the $220{ }^{\circ} \mathrm{C}$ and 120 min experiments, total lignin recovery is even $>100 \%$. These trends suggest that lignin degradation is negligible at the process conditions applied and that the lignin part missing in the distribution patterns consists of lignin not separated from the organosolv liquor. A mechanistic explanation for the improved lignin separation efficiency with pretreatment severity is lacking at the moment. However, larger lignin particles were observed during precipitation after high-severity organosolv experiments, which indicates that lignin (re)condensation reactions and nuclei formation might play a role (see also discussion on hemicellulose hydrolysis below).

3.2. Hemicellulose Hydrolysis. Hemicellulose hydrolysis increases significantly with temperature and time (i.e., pretreatment severity) as well as water content of the pulping solvent (Figure 4). Almost complete hemicellulose hydrolysis has occurred during the pure water (93\%) and $220{ }^{\circ} \mathrm{C}(95 \%)$ experiments. Hemicellulose hydrolysis is autocatalyzed by the $\mathrm{pH}$ decrease resulting from the formation of acetic acid upon hydrolysis of acetyl side groups. As discussed above for lignin, an increase of the acetone-water ratio leads to a higher $\mathrm{pH}$ of the organosolv liquor due to a change of the dissociation constant of acetic acid. Thus, hemicellulose hydrolysis decreases with the acetone proportion. A decrease of hemicellulose hydrolysis with organic solvent proportion has also been reported for ethanol-based organosolv pretreatment of willow wood. $^{14}$

The amount of monomeric xylose detected in the organosolv liquor is low at all process conditions with a maximum concentration of $1.3 \mathrm{~g} / \mathrm{kg}$ organosolv liquor (Table 3 ). At most, $5.8 \%$ of the xylan removed from the solid is present as monomeric xylose in the organosolv liquor (100\% pure water experiment). Most xylose is present as part of oligomeric sugar fragments. In the temperature series, the concentration of monomeric xylose in the organosolv liquor shows a maximum at $190{ }^{\circ} \mathrm{C}$. At lower temperature, the xylose formation by hemicellulose hydrolysis is dominant as compared to xylose dehydration to furfural. At higher temperature, xylose dehydration increases substantially, resulting in higher furfural concentrations. Maximum furfural concentration occurs at $205{ }^{\circ} \mathrm{C}$; above that temperature, conversion reactions of furfural become dominant.

The hemicellulose mass balances as shown in Figure 4, which include oligomeric xylose and furfural present in the organosolv liquor, are far from complete, especially at more severe process conditions. This is partly due to components present in the organosolv washing liquor, which has not been analyzed. Typically, the organosolv liquor is about $70 \% \mathrm{w} / \mathrm{w}$ of the acetone-water mixture used for the organosolv experiment (Table 3), which implies that about $30 \%$ of the products formed would be present in the washing liquor (assuming 100\% washing efficiency and neglecting processes that might change the amount of liquid present). Composition analysis of the washing liquor would therefore have only partially completed the hemicellulose mass balances.

The fact that the closure of the mass balance decreases with pretreatment severity suggests that a substantial part of the hemicellulose sugars has reacted further to nondetected products such as "humins" and condensation products of lignin with reactive aldehydes like furfural. Formation of the latter, which has been reported to form during organosolv alcohol pretreat- ment, ${ }^{5}$ would also (partially) explain the increase of the lignin separation efficiency with pretreatment severity to values exceeding $100 \%$, as discussed in section 3.1. In other words, part of the hemicellulose derivatives may have ended in the "lignin" precipitate obtained from the organosolv liquor. The same holds for proteins present in the raw material, because proteins are known to bind to lignin. ${ }^{22}$ However, it should be realized that the protein content of the raw material used is low $(0.2 \% \mathrm{w} / \mathrm{w} \mathrm{N})$. Characterization of the precipitates resulting from organosolv fractionation at different process conditions is required to elucidate these issues further.

3.3. Cellulose Recovery. Glucan recovery in the solid fraction is between $89 \%$ and $96 \%$ at all pretreatment conditions tested (Figure 5, sum "yield enzymatic hydrolysis" and "pretreated solid after enzymatic hydrolysis"). In other words, limited glucan hydrolysis occurs during organosolv pretreatment, which is confirmed by the low concentrations of glucose and its derivatives in the organosolv liquors (Table 3). Moreover, a part of the glucan hydrolysis observed can probably be attributed to glucan originating from the extractives or hemicellulose fractions rather than the cellulose fraction.

Similarly to xylose from hemicellulose, the amount of monomeric glucose in the organosolv liquor is relatively small, and most glucose is present in oligomeric form (Table 3). The monomeric glucose concentration decreases upon a higher acetone content or process severity, whereas that of the glucose dehydration product HMF increases.

3.4. Ash. The ash content of the pretreated wheat straw increases with pretreatment severity and is directly correlated to the pulp yield (Table 2). For all experiments at an acetone-water ratio $\geq 40 \% \mathrm{w} / \mathrm{w}, 63-69 \%$ of the ash originally present in the raw material remains in the pretreated solid (most likely $\mathrm{SiO}_{2}$ ). The other part of the ash, including soluble minerals like $\mathrm{KCl}$, is washed out during organosolv treatment. At lower acetone-water ratios, a larger fraction of the ash seems to be washed out (e.g., the ash recovery in the pretreated solid is $48 \%$ for the $100 \% \mathrm{w} / \mathrm{w}$ water experiment).

3.5. Enzymatic Digestibility. The glucose yield after $72 \mathrm{~h}$ of enzymatic hydrolysis is shown in Figure 6 for both the fresh and the pretreated wheat straw (for glucose concentration profiles during enzymatic hydrolysis, see the Supporting Information). Enzymatic digestibility of the cellulose fraction of the wheat straw improves substantially by acetone-based organosolv pretreatment at all process conditions applied (from $16 \%$ of the theoretical maximum glucose yield for fresh wheat straw to $31-87 \%$ for pretreated wheat straw). Enzymatic digestibility increases with pretreatment severity up to $87 \%$ of the glucan present in wheat straw pretreated at $205^{\circ} \mathrm{C}$. A further increase of the pretreatment temperature to $220{ }^{\circ} \mathrm{C}$ slightly decreases the enzymatic digestibility to $82 \%$. Taking into account the cellulose recovery of the organosolv pretreatment, a maximum overall enzymatic glucose yield of $80 \%$ has been obtained (205 ${ }^{\circ} \mathrm{C}$ experiment, Figure 5). Similar enzymatic hydrolysis degrees (up to $92 \%$ based on glucan content pretreated material, using 44 FPU/gr dry biomass) have been reported for glycerol-based organosolv pretreatment of wheat straw. ${ }^{23}$

The acetone-water ratio series shows optimal enzymatic hydrolysis of the cellulose fraction at 40:60\% w/w acetone-water (at $190{ }^{\circ} \mathrm{C}, 60 \mathrm{~min}$, Figure 6), which is between the optima for hemicellulose hydrolysis and delignification as discussed above (0:100 and 50:50\% w/w, respectively). In the literature, hemicellulose hydrolysis has been reported to substantially enhance enzymatic digestibility of lignocellulose. ${ }^{24-26}$ With respect to the delignification, reported results seem to be more ambiguous. 

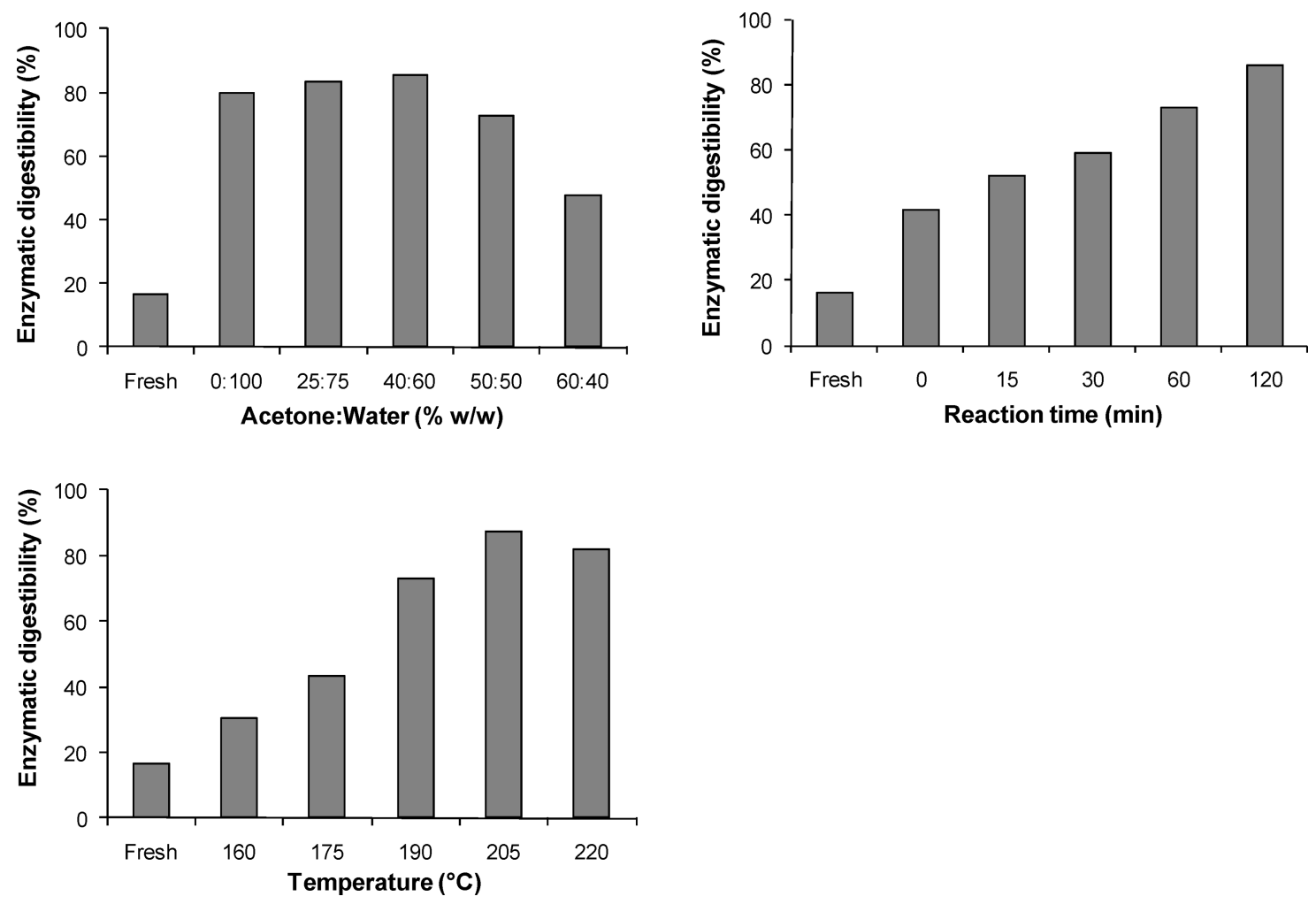

Figure 6. Enzymatic digestibility after $72 \mathrm{~h}$ enzymatic hydrolysis calculated on the basis of the glucan content of the pretreated wheat straw. Enzymatic digestibility is expressed as percentage of the theoretical maximum glucose yield.

For a number of different pretreatment technologies and types of biomass, delignification has been reported to enhance enzymatic digestibility. ${ }^{26-28}$ However, no correlation between the lignin content of the pretreated biomass and its enzymatic digestibility was found for, for example, ethanol and acetonebased organosolv pretreatment of softwoods. ${ }^{29,30}$ In this study, both hemicellulose hydrolysis and delignification seem to have a beneficial influence on the enzymatic cellulose digestibility. Pretreatment of wheat straw in pure water results in a substantial improvement of the enzymatic digestibility up to $80 \%$ without lignin removal from the solid (Figures 3 and 6, hemicellulose hydrolysis: 93\%). At the optimum acetone-water ratio for enzymatic digestibility $(40-60 \% \mathrm{w} / \mathrm{w})$, the enzymatic glucose yield is increased to $87 \%$ due to $68 \%$ delignification (hemicellulose hydrolysis: 70\%). The increase in enzymatic glucose yield by delignification is however relatively small. The beneficial influence of delignification, for which acetone in required, seems to be partly annulled by the corresponding lower hemicellulose hydrolysis. Finally, it should be kept in mind that these results have been obtained using a high enzyme dose. Loss of enzyme activity due to adsorption of enzymes to lignin ${ }^{26,31}$ probably plays a minor role at the high enzyme dose applied, but might become an important factor with accompanying costs for a biorefinery employing optimized enzyme doses.

For practical reasons, pretreated wheat straw samples were dried prior to enzymatic hydrolysis in this study. Although mild temperatures were applied, drying of pretreated lignocellulose has been reported to possibly deteriorate enzymatic digestibility. ${ }^{16,32}$ The effect of the drying for acetone-based organosolv pretreatment of wheat straw was studied by an additional organosolv experiment $\left(205{ }^{\circ} \mathrm{C}, 120 \mathrm{~min}, 50-50 \% \mathrm{w} / \mathrm{w}\right.$ acetone-water, see section 3.6). The obtained organosolv pulp after washing was divided into two; one half was dried according to the standard procedure, and the other half was washed with water to remove the acetone and kept wet until enzymatic hydrolysis. Drying the pretreated wheat straw was found to substantially slow the enzymatic hydrolysis within the first $24 \mathrm{~h}$ (46\% and $73 \%$ (dried) vs $61 \%$ and $83 \%$ (nondried) enzymatic cellulose digestibility after 4 and $24 \mathrm{~h}$, respectively) (see the Supporting Information). Already after $24 \mathrm{~h}$, maximum conversion was obtained for the nondried fraction. However, the enzymatic digestibility of the dried fraction increased further within the next $48 \mathrm{~h}$, resulting in $79 \%$ (dried) versus $82 \%$ (nondried) glucose yield after $72 \mathrm{~h}$. Optimization of the enzymatic hydrolysis process step was outside the scope of this Article, but direct enzymatic hydrolysis without intermediate drying seems a means to reduce enzymatic hydrolysis time and possibly enzyme dose.

3.6. Optimization Process Conditions. In this study, only the individual effects of the major process parameters on acetone-based organosolv fractionation of wheat straw were studied. For optimization of the process conditions, the interaction effect between process parameters should also be taken into account. Besides, acetone-based organosolv fractionation of wheat straw yields multiple products, that is, celluloseenriched pulp for enzymatic hydrolysis, hemicellulose derivatives, and lignin. Because this study shows that no single set of process conditions exists at which maximum yields of all products occur, final optimization of the process conditions should be based on the (net) revenues of these products.

The trends shown in Figures 3-6 can be used as a starting point for future optimization of the process toward the desired product(s). As an example, an additional organosolv experiment was performed at $205{ }^{\circ} \mathrm{C}, 120 \mathrm{~min}$, and $50-50 \% \mathrm{w} / \mathrm{w}$ acetone-water to potentially further improve delignification and enzymatic digestibility. This experiment resulted in the highest delignification degree obtained in this study (83\%), while hemicellulose hydrolysis was $89 \%$ (cellulose recovery: $92 \%$ ). Remarkably, the overall enzymatic glucose yield was not 
improved as compared to $60 \mathrm{~min}$ pretreatment at identical conditions including intermediate drying $(79 \%$ vs $80 \%$ based on the glucan content of fresh wheat straw). The higher glucose concentration obtained in the enzymatic hydrolysis (19.9 vs 18.5 $\mathrm{g} / \mathrm{L}$ glucose after $72 \mathrm{~h}$ ) (see the Supporting Information) is nullified by the lower pulp yield ( 44.9 vs $48.7 \% \mathrm{dw}$ ).

\section{Conclusions}

Acetone-based organosolv pretreatment was found to effectively fractionate wheat straw into its main constituents and enhance the enzymatic hydrolysis of its cellulose fraction. Pretreatment severity had a major influence on the delignification and hemicellulose hydrolysis. The solvent-water ratio was found to influence delignification and hemicellulose hydrolysis by its effect on lignin solubility and $\mathrm{pH}$. Pretreatment in 50: $50 \% \mathrm{w} / \mathrm{w}$ acetone-water during $1 \mathrm{~h}$ at $205{ }^{\circ} \mathrm{C}$ resulted in $82 \%$ hemicellulose hydrolysis, $79 \%$ delignification, and $93 \%$ cellulose recovery. A substantial part of the sugars formed upon hemicellulose hydrolysis seems to have reacted further including possible formation of lignin-furfural condensation products. After organosolv pretreatment, the glucan content of the wheat straw had increased from $35 \%$ to $65 \% \mathrm{w} / \mathrm{w}$, and its enzymatic digestibility had increased from $16 \%$ to $87 \%$.

Future research should primarily focus on characterization of the hemicellulose derivatives and the lignin product as well as their valorization possibilities. Final optimization of the process conditions should be done on the basis of the (net) revenues of the products, taking into account interaction effects between process parameters. Other important aspects for further development of acetone-based organosolv fractionation as a primary biorefinery technology include the recycling of the acetone as well as the energy use and costs associated with this process.

\section{Acknowledgment}

We thank Philippe Coudor, Ron van der Laan, and Arjan Smit for their contribution to the experimental work. Abengoa Bioenergía Nuevas Tecnologías and Genencor kindly provided the wheat straw and the enzyme mixture Accellerase 1000, respectively. This research was financed by the EU-FP6 integrated project BioSynergy (EC contract 038994-SES6) and the Dutch Ministry of Economic Affairs as part of the ECN biomass research program.

Supporting Information Available: Glucose concentration during profiles enzymatic hydrolysis of fresh and pretreated wheat straw. This material is available free of charge via the Internet at http://pubs.acs.org.

\section{Literature Cited}

(1) Kumar, P.; Barrett, D. M.; Delwiche, M. J.; Stroeve, P. Methods for pretreatment of lignocellulosic biomass for efficient hydrolysis and biofuel production. Ind. Eng. Chem. Res. 2009, 48, 3713-3729.

(2) Mosier, N.; Wyman, C. E.; Dale, B. E.; Elander, R. T.; Lee, Y. Y.; Holtzapple, M.; Ladisch, M. R. Features of promising technologies for pretreatment of lignocellulosic biomass. Bioresour. Technol. 2005, 96, 673686.

(3) Aziz, S.; Sarkanen, K. Organosolv pulping - a review. TAPPI J. 1989, 72, 169-175.

(4) Pye, E. K.; Lora, J. H. The Alcell process - a proven alternative to Kraft pulping. TAPPI J. 1991, 74, 113.

(5) Zhao, X.; Cheng, K.; Liu, D. Organosolv pretreatment of lignocellulosic biomass for enzymatic hydrolysis. Appl. Microbiol. Biotechnol. 2009, $82,815-827$.
(6) Arato, C.; Pye, E. K.; Gjennestad, G. The Lignol approach to biorefining of woody biomass to produce ethanol and chemicals. Appl. Biochem. Biotechnol. 2005, 123, 871-882.

(7) Pan, X.; Gilkes, N.; Kadla, J. F.; Pye, K.; Saka, S.; Gregg, D.; Ehara, K.; Xie, D.; Lam, D.; Saddler, J. N. Bioconversion of hybrid poplar to ethanol and co-products using an organosolv fractionation process: optimization of process yields. Biotechnol. Bioeng. 2006, 94, 851-861.

(8) Brosse, N.; Sannigraphi, P.; Ragauskas, A. Pretreatment of miscanthus $x$ giganteus using the ethanol organosolv process for ethanol production. Ind. Eng. Chem. Res. 2009, 48, 8328-8334.

(9) Bozell, J. J.; Holladay, J. E.; Johnson, D.; White, J. F. Top valueadded chemicals from biomass. Vol. II - results of screening for potential candidates form biorefinery lignin; Report PNNL-16983; U.S. Department of Energy: Washington, DC, 2007.

(10) Lora, J. H.; Glasser, W. G. Recent industrial applications of lignin: a sustainable alternative to nonrenewable materials. J. Polym. Environ. 2002, $10,39-47$.

(11) Muurinen, E. Organosolv pulping. A review and distillation study related to peroxyacid pulping. Ph.D. thesis, Faculty of Technology, University of Oulu, Oulu, Finland, 2000.

(12) Jiménez, L.; de la Torre, M. J.; Bonilla, J. L.; Ferrer, J. L. Organosolv pulping of wheat straw by use of acetone-water mixtures. Process Biochem. 1998, 33, 401-408.

(13) Jiménez, L.; García, J. C.; Pérez, I. Influence of cooking variables in the organosolv pulping of wheat straw using mixtures of ethanol, acetone, and water. TAPPI J. 2003, 2, 27-31.

(14) Huijgen, W. J. J.; Van der Laan, R. R.; Reith, J. H. Modified organosolv as a fractionation process of lignocellulosic biomass for coproduction of fuels and chemicals. Proceedings of the 16th European Biomass Conference \& Exhibition; Valencia, Spain, 2008.

(15) Macfarlane, A. L.; Prestidge, R.; Farid, M. M.; Chen, J. J. J. Dissolved air flotation: a novel approach to recovery of organosolv lignin. Chem. Eng. J. 2009, 148, 15-19.

(16) National Renewable Energy Laboratory (NREL) Chemical analysis and testing laboratory analytical procedures. NREL, Golden, CO; http:// www.nrel.gov/biomass/analytical_procedures.html, 2009.

(17) Technical Association of the Pulp and Paper Industry (TAPPI) Standard Test Methods. Norcross, GA; http://www.tappi.org/, 2009.

(18) Ghose, T. K. Measurement of cellulase activities. Pure Appl. Chem. 1987, 59, 257-268.

(19) Yee, H. Y.; Goodwin, J. F. Evaluation of some factors influencing o-toluidine reaction with glucose. Anal. Chem. 1973, 45, 2162-2165.

(20) Li, J.; Henriksson, G.; Gellerstedt, G. Lignin depolymerization/ repolymerization and its critical role for delignification of aspen wood by steam explosion. Bioresour. Technol. 2007, 98, 3061-3068.

(21) Heitz, M.; Brown, A.; Chornet, E. Solvent effects on liquefaction: solubilization profiles of a Canadian prototype wood, Populus deltoides, in the presence of different solvents. Can. J. Chem. Eng. 1994, 72, 10211027.

(22) Pan, X. J.; Xie, D.; Gilkes, N.; Gregg, D. J.; Saddler, J. N. Strategies to enhance the enzymatic hydrolysis of pretreated softwood with high residual lignin content. Appl. Biochem. Biotechnol. 2005, 121, 1069-1079.

(23) Sun, F.; Chen, H. Evaluation of enzymatic hydrolysis of wheat straw pretreated by atmospheric glycerol autocatalysis. J. Chem. Technol. Biotechnol. 2007, 82, 1039-1044.

(24) Kabel, M. A.; Bos, G.; Zeevalking, J.; Voragen, A. G. J.; Schols, H. A. Effect of pretreatment severity on xylan solubility and enzymatic breakdown of the remaining cellulose from wheat straw. Bioresour. Technol. 2007, 98, 2034-2042.

(25) Mesa, L.; González, E.; Ruiz, E.; Romero, I.; Cara, C.; Felissia, F.; Castro, E. Preliminary evaluation of organosolv pre-treatment of sugar cane bagasse for glucose production: Application of $2^{3}$ experimental design. Appl. Energy 2010, 87, 109-114.

(26) Yang, B.; Wyman, C. E. Effect of xylan and lignin removal by batch and flowthrough pretreatment on the enzymatic digestibility of corn stover cellulose. Biotechnol. Bioeng. 2004, 86, 88-95.

(27) Öhgren, K.; Bura, R.; Saddler, J.; Zacchi, G. Effect of hemicellulose and lignin removal on enzymatic hydrolysis of steam pretreated corn stover. Bioresour. Technol. 2007, 98, 2503-2510.

(28) Hendriks, A.; Zeeman, G. Pretreatments to enhance the digestibility of lignocellulosic biomass. Bioresour. Technol. 2009, 100, 10-18.

(29) Pan, X.; Xie, D.; Yu, R. W.; Lam, D.; Saddler, J. N. Pretreatment of lodgepole pine killed by mountain beetle using the ethanol organosolv process: fractionation and process optimization. Ind. Eng. Chem. Res. 2007, 46, 2609-2617.

(30) Araque, E.; Parra, C.; Freer, J.; Contreras, D.; Rodríguez, J.; Mendonça, R.; Baeza, J. Evaluation of organosolv pretreatment for the conversion of Pinus radiata D. Don to ethanol. Enzyme Microb. Technol. 2008, 43, 214-219. 
10140 Ind. Eng. Chem. Res., Vol. 49, No. 20, 2010

(31) Berlin, A.; Balakshin, M.; Gilkes, N.; Kadla, J.; Maximenko, V.; Kubo, S.; Saddler, J. Inhibition of cellulase, xylanase and $\beta$-glucosidase activities by softwood lignin preparations. J. Biotechnol. 2006, 125, 198209

(32) Esteghlalian, A. R.; Bilodeau, M.; Mansfield, S. D.; Saddler, J. N. Do enzymatic hydrolyzability and Simons' stain reflect the changes in the accessibility of lignocellulosic substrates to cellulase enzymes? Biotechnol. Prog. 2001, 17, 1049-1054.
(33) $\mathrm{Ni}, \mathrm{Y}$.; Hu, Q. Alcell lignin solubility in ethanol-water mixtures. J. Appl. Polym. Sci. 1995, 57, 1441-1446.

Received for review June 8, 2010 Revised manuscript received August 27, 2010 Accepted September 9, 2010

IE101247W 